\title{
Producing 3D applications for urban planning by integrating 3D scanned building data with geo-spatial data
}

\author{
Yonghui Song, Research Institute for the Built and Human Environment (BuHu), University of \\ Salford, UK \\ Email: Y.H.Song@Salford.ac.uk, \\ Hongxia Wang, BuHu, University of Salford, UK \\ Email: $\underline{\text { H.Wang@Salford.ac.uk }}$ \\ Andy Hamilton, BuHu, University of Salford, UK \\ Email: A.Hamilton@Salford.ac.uk \\ Yusuf Arayici, BuHu, University of Salford, UK \\ Email: Y.Arayici@salford.ac.uk
}

\begin{abstract}
Visual Information Systems for urban planning can be produced in a variety of ways. In this paper we give an account of research into integrating scanned data with urban data sets to produce 3D applications that span built environment spatial scales from building elements to the whole city. In our research, 3D laser scanner is used to capture 3D building models as a way of developing visual 3D presentations. In order to use 3D building models for urban environment, relevant standards are reviewed and the integration of 3D building models with urban scaled geo-spatial data are explored. In the recent EU-funded IntelCities(2004-2005) and Virtual Environment Planning System (VEPS, 2004-2008) research projects, the authors have worked on capturing an existing building in digital form and using 3D data in building refurbishment projects and visualisation of urban environment in planning consultation. The paper introduces the ways of producing 3D applications using integrated data from 3D scanning with geo-spatial datasets. The IntelCities application shows an application for building features survey such as windows and doors, and holistic review of the building's surroundings regarding historical building refurbishment. The application developed in the VEPS demonstrates the potential of delivering web-based integrated consultation services using 2D/3D visualisation. This can be useful to achieve holistic analysis in urban planning projects.
\end{abstract}

Keywords 3D Geo-visualization, 3D data aquisation, City model, Data integration, IFC, City GML, Web Service, GIS, VR, 3D application

\section{Introduction}

\subsection{Background research}

The UK government, and governments in most of the developed world, are providing citizens with web based services that are delivered directly to the home. Governments also require Local Authorities to provide services to citizens. Many of these services are specifically concerned with urban development, such as the need to engage citizens in 
decisions concerning a retail park, or a new swimming pool. To deliver these services cities need to develop web applications that can show a wide range of information in a 3D environment. Furthermore these applications need to be developed in such a way that they can be incrementally updated to reflect the changing face of the city. To acheive this end application developers face a number of challenges.

Generally, 3D city models are created using CAD tools. There have been many successful projects which have produced detailed and realistic 3D city models for a diverse range of cities (Dodge 1998; Hammad 1999; Bulmer 2001; Jepson 2001). These city models are created with accurate building models compiled with ortho-photographs and achieved impressive, realistic urban environment (Chan 1998). However, the creation of 3D city models using CAD tools and ortho-phtographs are facing challenges. Two of the challenges are discussed below.

The first challenge is that the creation of 3D city models with CAD tools is labour-intensive, time-consuming and expensive. Recently developed and emerging technologies have the potential to make the creation of the 3D city models more effective. GIS-based methods combine 3D techniques with GIS to improve the visualization ability of GIS. However, GIS-based 3D models are restricted to block models or block models with texture mapping, which lack of detailed information and limited quality of the visual realism due to the lack of detailed 3D spatial data for man-made objects. Aquiring 3D data is difficult, but a useful technology is photogrammetry which provides an economic mean to acquire truly 3D models based on aerial images for the coverage of a wide urban area. However this technology has limitations. For example, it seems quite difficult to capture the detailed building structure by using photogrammetry. An emerging technology for 3D data capture is the laser scanning which is a quick and efficient way of digital data capture for a building. However it should be noted that the efficient processing of scanned data to produce virtual models of buildings is still the subject of research. This will be discussued in this paper.

The second challenge is that the datasets underlying these 3D city models are in diverse formats. It is difficult to satisfy the frequent updating and extending requirement for the developing urban environments. Different tools have their own ways to describe urban environments. A standard description of the 3D city model is needed in order to support various applications. It is also necessary to develop appropriate data processing and converting mechanism, standard format of data outcome make the data model usable for urban environment based applications.

These two challenges are the focus of this paper. We will show how recent research undertaken by the authors not only addreses the challenges individually but also, by considering the way scanned data can be used in large urban models, provides for the integration of data sets across a wider spatial scale than is currently available in cities.

In this paper, two research projects in which the authors were involved, IntelCities and VEPS, have been reviewed regarding the development of 3D scanning technologies and data integration in urban models. 
The Intelligent Cities (IntelCities) project (http://www.intelcitiesproject.com/) was an integrated project funded by the European Commission (EC) Information Society Technologies programme under framework 6 (6.8 million Euro, January 2004 to October 2005). The aim of the IntelCities project was the development of open, secure, interoperable and re-configurable e-Government services at the city level.

For IntelCities the authors developed the Building Data Integration System as a concept system to illustrate how digitized historic building data can be integrated with other types of city data (Hamilton et. Al., 2005). 3D scanning techonology was used to facilitate building reverse-engineering (producing data models and plans for buildings from surveying information). Due to the 3D scanning technology having high accuracy, (e.g Reigl 390 is accurate to $5 \mathrm{~mm}$ with a range of 350 Metres) this allows for the development of accurate building plans. A series of laser scans were taken to capture 3D data of Jactin House in Manchester for refurbishment purpose. This work is detailed in Section 2 and 4.

The second project is the Virtual Environmental Planning Systems (VEPS) project (2004-2008). VEPS project is an INTERREG IIIB funded, 4 million Euro European project (E109) was led by the Environment Agency for England and Wales (EAEW). A key activity in VEPS was the use of a variety of data sets, including high resolution three dimensional (3D) data from both aerial and ground based laser scanning, for use within Virtual Reality (VR) visualization software and the subsequent delivery of the VR environment via the Internet and World Wide Web. Through the VEPS project, issues of building data capture and building data integration were to be considered at a larger scale through investigating data standardization, modelling, interoperability and integration with other (VR) systems (Counsell et. Al., 2008). This will be discussed in Section 4.

\subsection{Overview of the paper}

For the urban built environment, stakeholders rely heavily on information from various sources in the urban planning decision-making process. There is an increasing need to seamlessly integrate the relevant datasets at both building and urban scales. The capture and integration of relevant data for the urban built environment has always been a challenge due to the high cost and the heterogeneous nature of the datasets (Wang 2007). In our research, historic building data is captured using the laser scanning technologies and are processed into a CAD/IFC building model. For buildings which do not have digital format model available, it can be more effective and quicker to produce the skelecton of buildings using drawing softwares based on the 3D point clound data than drawing from scratch. Further more, the authors worked on the integration of digital building data with surrounding geospatial data which can bridge the gap between the construction and urban domain and support urban development control and construction process. This extends the use of datasets beyond their original collection purposes and facilitates the data sharing and interoperablity across domains. In this way, the construction industry and urban development can both benefit by reducing data capturing cost.

The paper is in 5 sections. In Section 2, the paper reviews 3D laser scanning technologies and how they are used; In Section 3, the paper discusses the needs for standards in 3D city models in order to support various applications. Specifically, the paper discussed the 
emerging 3D city model standard CityGML, an application scheme based on OGC's GML 3.1. In section 4 it reviews the integrating of 3D scanned data with 3D city models to produce a model that has a spatial scale from the smallest building elements to the whole of the city. This is through the review of two research project. In section 5 the paper is concluded with a review of the production of $3 \mathrm{D}$ applications for urban services using the integration of $3 \mathrm{D}$ scanned building data and 3D city data.

It should be noted that the focus of the paper is not the processing of scanning data, rather it focuses on investigation of the potential and benefit of integrating building scale 3D models derived from 3D scanning technologies to produce city scale 3D models.

\section{Using 3D Laser Scanning Technologies for Built}

\section{Environment Modelling - Jactin House 3D scanning}

Laser scanning technology can be used by construction professionals to analyse 3D building data and as way of developing a highly visual 3D presentation tool (Arayici et. Al., 2005). In IntelCities FP6 Integrated Project (see section 1.1), the use of 3D Laser Scanner had illustrated how an unusual building with many curved elements can be captured in digital form with an accuracy that would not be possible without a 3D scanner.

3D laser scanning provides a way of getting accurate surface information of physical objects without contacting it. This is very useful for modelling fragile objects or unreachable objects. In some cases, normal surveying of an object can be dangerous due to physical structure etc. in all of this situation 3D scanning technologies have big advantages. That is why 3D scanning technologies have the potential to be widely used in archaeology, digital building survey, and site monitoring applications and so on.

In the IntelCities project,the 3D building data of Jatin House was captured using a 3D scanner. With the 3D scanner, it is very convenient to take internal and external measurements to provide accurate plans, sections and elevations. The potential to accurately capture information of the inaccessible and potentially hazardous areas such as pitched rooftops and workplaces makes it possible to acquire building information difficult to capture in other ways. (Hamilton et. Al., 2005)

By post-processing the captured spatial data, outputs for different purposes can be obtained such as CAD modelling, physical modelling by prototyping and visualization in different platforms. This kind of building reverse-engineering facilited by the 3D scanner can be very accurate due to the 3D scanning technology having high accuracy (e.g Reigl 390 is accurate to $5 \mathrm{~mm}$ with a range of 350 Metres). This allows for the development of accurate building plans.

The following Figure 1 shows the raw scans of the interior and exterior of the Jactin House. They are conducted with several different scan positions and then merged together. 

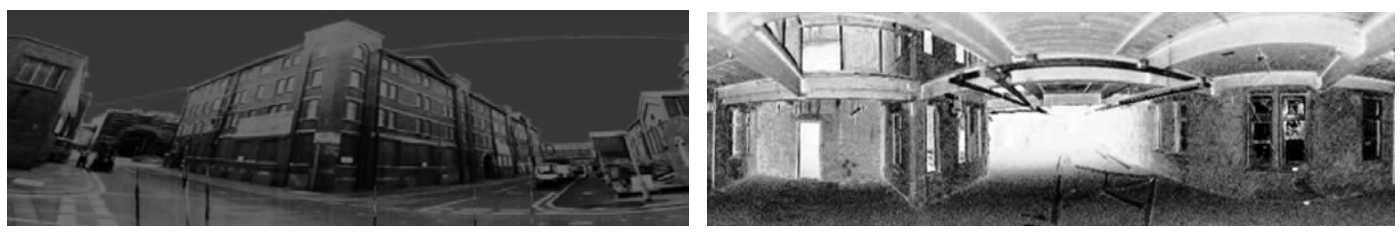

Figure 1 Exterior scans around Jactin house (left) and interior scans inside the Jactin House (right)

By having sufficient overlap scan at the entrance area of Jactin House, the exterior and interior scans were registered (merged) as well to form a complete Jactin House mesh model. A CAD model was created by a combination of using of a point cloud data software 'Polywork' and the point cloud modeler and CAD software 'Microstation' (Figure 2)

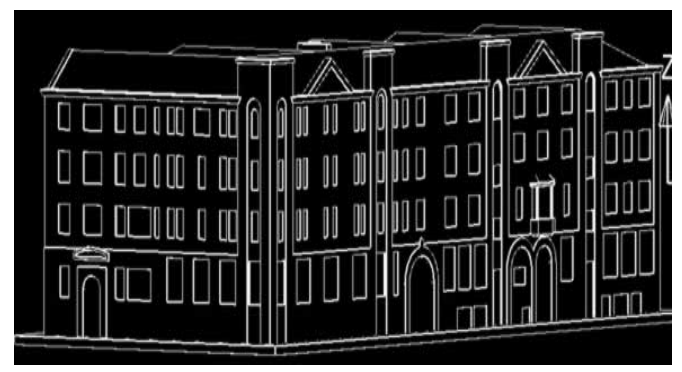

Figure 2 Jactin House CAD model is developed.

The scanning work shows that using laser scanning technologies is an effective way of producing detailed CAD building models. The authors believe that using 3D scanning technologies is one way of meeting current challenges especially quickly and efficiently capturing detailed 3D models.

It should be noted, althouth 3D scanner can obtain sufficient information of existing buildings, the post-processing can still be complex and time consuming depending upon how detailed the information needs to be. Achieving more automatisation in the post processing of the scanned data can make the process less complex and time consuming.Recent researchers in this area has made good progress it (Wang 2008). This paper however will not focus on the automatisation, instead it will put the emphasis on integrating the CAD model derived from ground based scanning with urban scale 3D model to produce 3D urban system application.

In section 4.1, the paper will revisit the Jactin House case study, about its integration with surrounding area 3D model to produce a 3D application.

\section{3D city model and building model}

As discussed in the Section 1 the creation of the 3D city model using traditional CAD tools is facing challenges. The work introduced in the Section 2 shows that using laser scanning technologies is an efficient way of producing detailed CAD building models. This section focuses on how to use CAD building models in urban environmental modelling. The emerging 3D data standards and converting between different standards are discussed. 


\subsection{D City Model and CityGML}

Section 1 has shown that due to the variation of 3D data formats in the market, it is difficult to satisfy the frequent updating and extension requirement for developing urban environments. Different tools have their own ways to describe urban environments. At the building scale many organisations with an interest in the construction industry have developed Industry Foundation Classes, IFCs, to provide a unified system describing all aspects of a building. At the urban scale a standard description of the 3D city model is needed in order to support various applications. The emerging 3D city model standard, CityGML, is such a standard description. These two systems are discussed in this section, with an account of recent work by the authors to integrate IFC and CityGML in order to achieve a unified model for the Built Environment across the building and urban scales.

CityGML is an application scheme based on OGC's GML 3.1. CityGML holds not only geospatial information but also supports a semantic model of city objects (http://www.citygml.org/). CityGML not only represents the graphical appearance of city models but especially takes care of the semantic representation, thematic properties, taxonomies and aggregations of digital terrain models, sites (including buildings, bridges, tunnels), vegetation, water bodies, transportation facilities and city furniture (Kolbe, 2005). The ability of maintaining different levels of detail makes it suitable for small and large area utilizations. The underlying model differentiates five consecutive levels of detail (LoD), where objects become more detailed with increasing LoD, both in geometry and thematic differentiation (Kolbe 2006).

\subsection{CAD Building Model and IFC}

Currently, there are many different types of CAD software in support of building design. Each CAD system from different vendors has its own method of describing geometry, both mathematically and structurally. Most CAD models use proprietary data formats and are stored as files in a file system. As one de-facto data standard for CAD applications, AutoCAD Drawing Interchange Format (DXF) is probably one of the most widely supported vector formats in the world today.

The IAI, an international cooperation of more than 650 members drawn from more than 20 countries (http://www.iai-international.org/), pioneered international technical cooperation to define a single building model as one authoritative semantic definition of building elements, their properties and interrelationships (Howell 2003). This work has largely been successful with its IFC Model now endorsed as an ISO standard (ISO/PAS 16739).

IFC is a non-proprietary set of internationally standardised object definitions for use in the construction industry The IFC model describes full 3D geometry but also relationships, process, material, cost and other behaviour data. Integrating a CAD model with IFC enables the accurate geometric representation to be integrated with structural and behaviour elements and facilitates links with external applications (Ding 2003).

IFC was designed to support the whole life cycle of a facility from planning, through construction and usage, to its demolition. In contrast to common 2D and 3D geometry data 
formats (e.g. DXF files), IFC are capable of modelling much attribute and meta-information related to the geometry.

\subsection{Building models in urban environment and IFC's conversion into CityGML}

Buildings are one of the most important elements within urban built environment. According to Fuchs's survey, 95\% of stakeholders identified three-dimensional building data to be of most interest in digital city models (Fuchs 1998). In a physical sense, a city is a collection of buildings. Good three-dimensional models of buildings are important for a variety of tasks including urban planning, urban management, simulation, disaster recovery etc. Digitalized 3D building models have been employed to support planning tasks by exploration, guiding, public participation and visual impact (Shiode 2001; Yao 2003)

Building descriptions in GIS have simple geometric descriptions, mainly, only a building's footprint. This information clearly is not sufficient to determine how a building is perceived as part of the public domain let alone the analysis and simulation for professionals. Sometimes buildings are represented by their walls and roofs. Fuchs reports high interest in roofs, as the size of the smallest element is critical for representing front details and overhanging elements (Fuchs 1998). More rarely windows, doors, small balconies, levelled streets and pavements are reconstructed (Arena2000, 1999). It is nescessary to convert the detail IFC building model into the 3D city model.

In a recently completed $\mathrm{PhD}$ by one of the authors, an IFC building model was converted into CityGML through Building Feature Service (BFS) (wang 2007). BFS was designed to retrieve and convert the IFC building model. The BFS can directly access building information sources which can be IFC/IFCXML files, OO building model database etc. It allows a client to query building features on the Web and convert the detailed building feature description into a CityGML document.

A prototype of BFS has been implemented (Wang 2007). The test building is Jactin House in the Ancoats area of Manchester. The Jactin House data was first captured by using a 3D laser scanner and was processed into an IFC building model. The BFS was developed as an ASP.Net web service by using C\# programming language based on the Microsoft .Net framework. The process of generating a CityGML document from IFC building model included three main tasks: manipulating IFC documents, coordinating conversion and generating service output in CityGML/GML. The implmentation diagram is hown in Figure 3

For manipulating IFC documents, there are some toolkits like IFCsvr, EDM and EuroStep etc. In this prototype, the IFC document manipulation is implemented by using a freeware IFCsvr ActiveX component (IMS 2002). The main reason of choosing it is because it is freeware and easy to embed in the development as an ActiveX components. The shortcoming is that ActiveX components can only be used in Microsoft's Window platforms. 


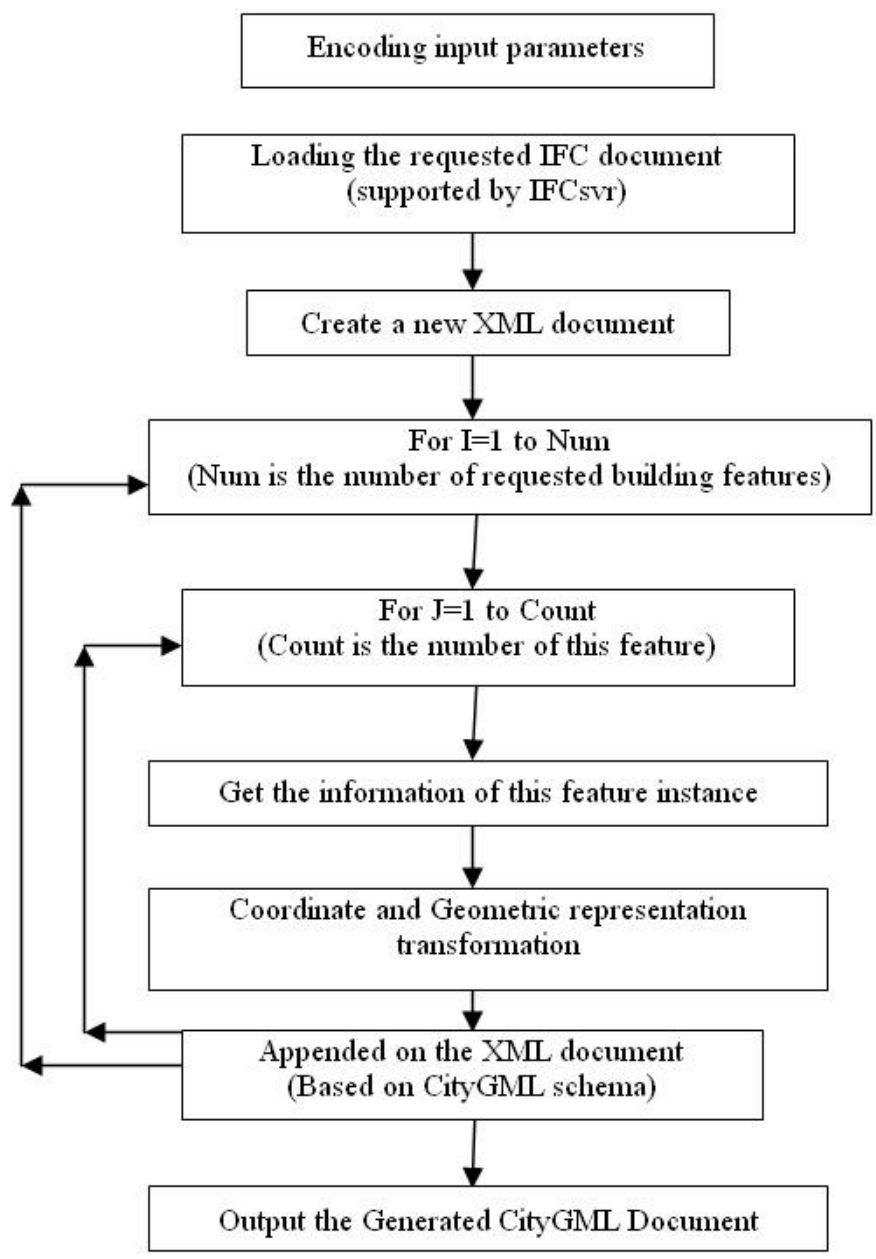

Figure 3 The implementation process of IFC to CityGML

The second task is to transform the building elements from IFc to CityGML. The first transformation is from a Local Coordination System into the World Coordination System of IFC buildings model. The transformation matrix can be calculated based on the relationship between these building elements, specifically in IfcLocalPlacement's PlacementRelTo and RelativePlacement attributes in the IFC document. The second transformation is from the geometric type in IFC into the geometric reprenstation in CityGML.

An XML document is then generated based on the CityGML schema definition. The System.Xml namespace in Microsoft .Net framework provides standards-based support for processing XML files. It is fairly easy to call the relevant functions for generation of XML documents based on CityGML schema.

The implementation details can be seen in one of the authors' PhD thesis (Wang 2007). The following Figure 4 shows the integration results of the conveted 3D building model (from IFC) and surrounding building footprint (from GIS) in a CityGML viewer. 


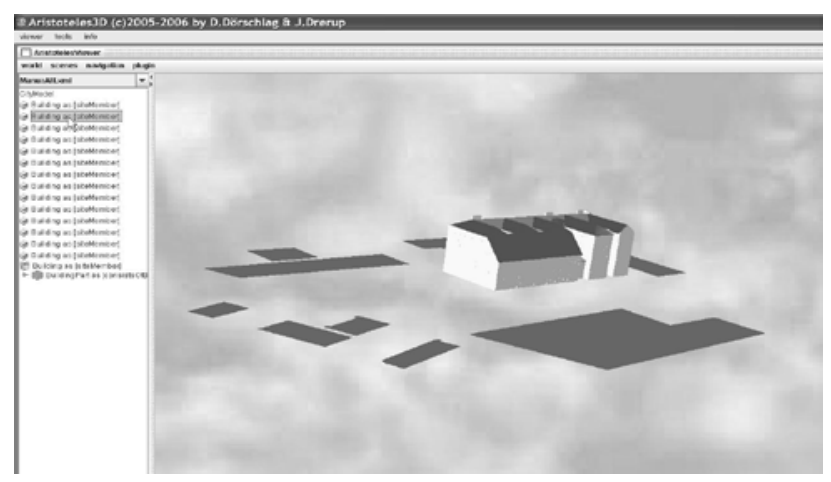

Figure 4 The integrated CityGML file displayed in Aristoteles3D viewer

\section{IntelCities and VEPS 3D application}

This paper mentioned the IntelCities and Virtual Environmental Planning Systems (VEPS) project in Section 1. This section introduces the IntelCities and VEPS system applications from a special angle of utilizing 3D scanning data. In other words, this section shows that 3D scanning technologies are used to provide 3D data for building 3D applications for urban activities. This was done by integrating scanned 3D building data with the city scaled spatial data.

Section 4.1 reviewed the IntelCities application based on the integration of building CAD model from scanned data with the surrounding city 3D model, and the services the application can provide.. Section 4.2 is about the integration of scanning data with other VEPS data sources, and Section 4.3 is an introduction of VEPS application design.

\subsection{IntelCities Application -outcome of Jactin House case study}

In Section 2, we reviewed the scanning technologies and how Jactin House was scanned and to further produce 3D CAD model. This section briefly reviews the 3D application which integrates CAD model derived from 3D scanned building data and surrounding city model..

During IntelCities, Laser scanner technology was used to assist with the refurbishment process. To guide this case study in IntelCities project, a fictitious "Gaudi Bank" scenario was created as a typical multi-national development project. In this scenario, the Gaudi Bank, based in Spain, with branches in the UK, is planning to set up a training centre in Manchester for staff working in the UK. The focus building is Jactin House in East Manchester. This is the proposed location of the training centre for Gaudi Bank. The structural data of Jactin House was obtained by using a 3D scanner. The data about the surrounding area was obtained from an OS Land-line map. And other information such as public transport etc was also collected and stored in a database with reference to the 3D data objects and 2D map objects. By editing and integrating this data, a multi-dimensional model of the building and the urban area was created to be used for decision-making processes. A system called "Built environment Data Integration System” (BDIS) has been produced to use the combined building scale and urban scale data to give a wide scaled view of a city environment. Various spatial data from different sources have to be converted into appropriate formats necessary for the integration: 2D geo-spatial data, 3D Industry Foundation Classes (IFC) building data 
(captured by 3D scanning) and non-spatial data. Then the system can be used to provide functionality such as a data surveying report, and even generate a 3D representation of all windows and doors of the House (Song et. Al,. 2007) see Figure 5.
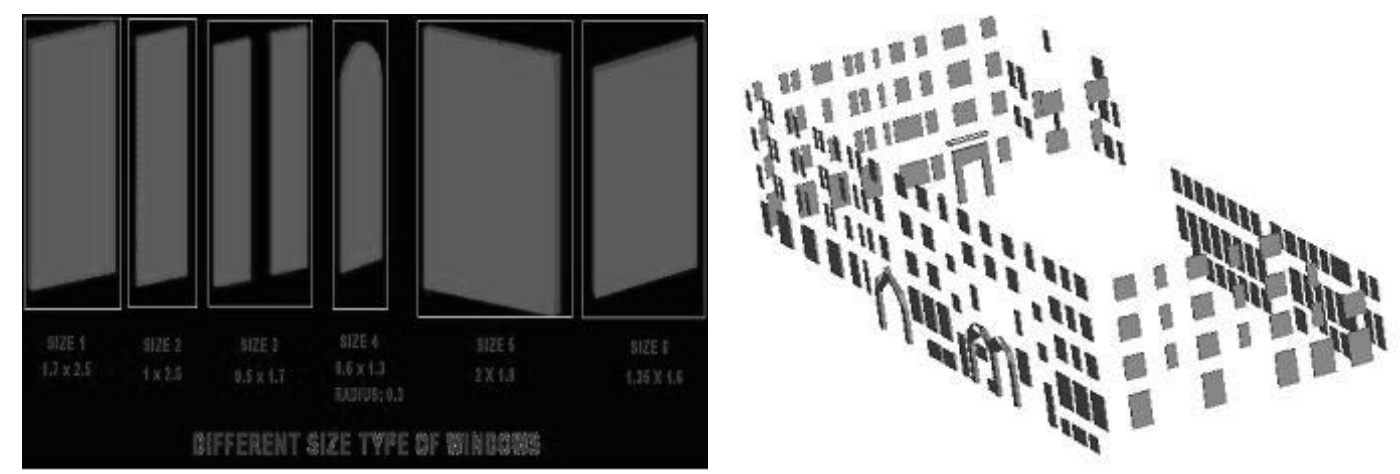

Figure 5 Left, images of windows generated by BDIS; Right, 3D VRML model of just windows and doors in Jactin House

The case study shows the laser scanning greatly improved the process of data capture compared to the traditional way of surveying for refurbishment, in which data capture was a time consuming task. By means of laser scanner technology, the building data can be captured in a short time period and stored in electronic format which can be shared between the stakeholders situated in different locations, apart from providing a faster, better quality and more precise analysis and feature detection for building surveys (Arayici et al., 2004). The research pointed out that the use of the 3D laser scanner has enormous potential to benefit building surveyors and their clients in terms of accuracy, speed and productivity in plan preparation and then to extend the range of services offered through modelling applications.

The ideas behind this research is data integration (Hamilton et. Al., 2005). The 3D scanned building models were mapped into IFC schema (Arayici et al., 2005; Tanyer et al., 2005; Wang and Hamilton, 2005), and were then saved into a centralized database. The following Figure 6 demonstrate the conceptual mode of the BDIS application. In this way, the 3D scanning data is integrated with other data sources. This enabled services based on the integrated data set to be provided to its users. Thus the scanned data is ready for use by a variety of users such as for building refurbishment. For instance, construction professionals are able to see the building in 3D and do a "building survey" from their office. Also for example, it is possible to generate a 3D representation of all Windows and doors of Jactin House (see Figure 5) and even generate a report about windows and doors in Jactin House (See Figure 7). 


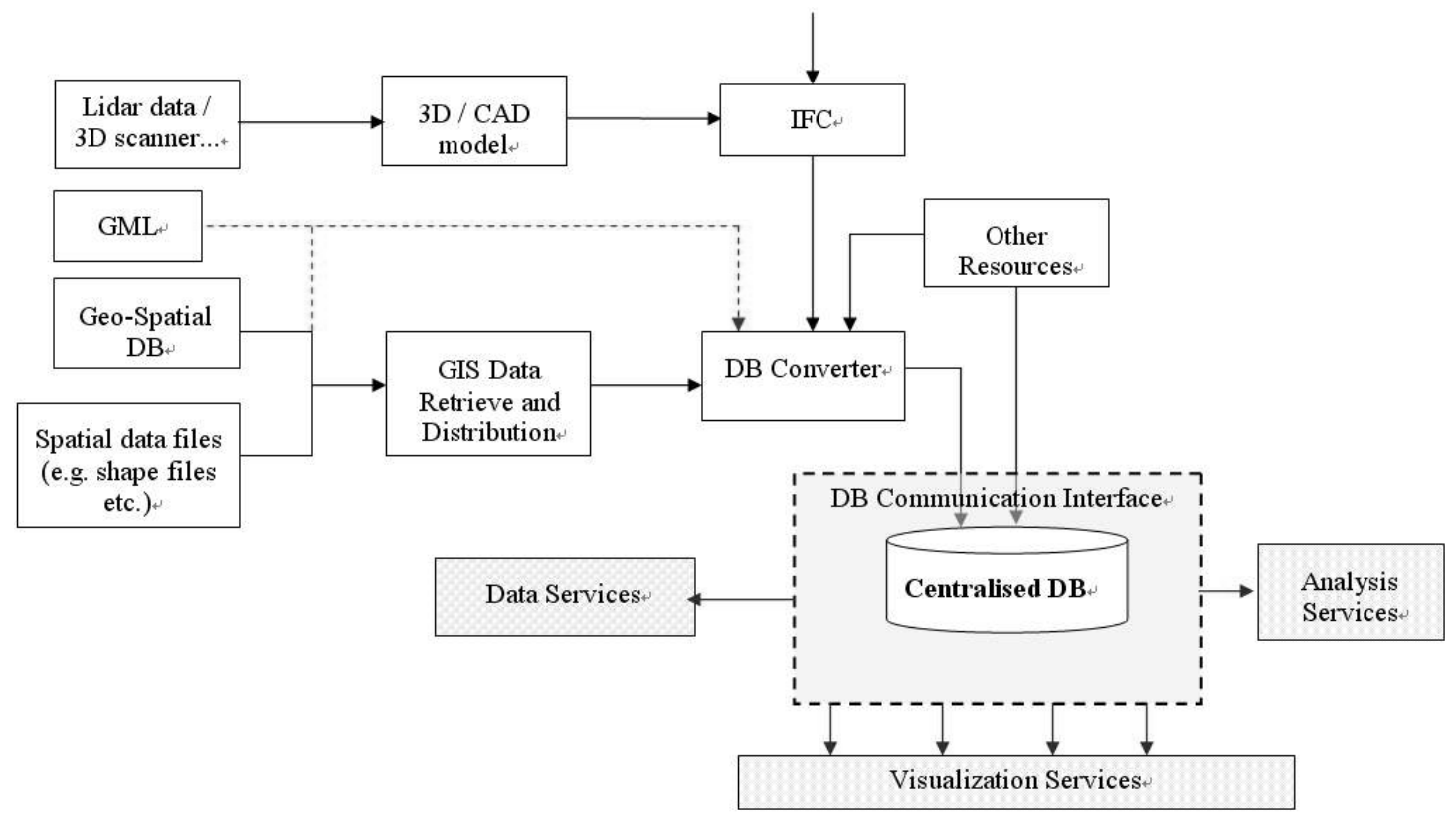

Figure 6: IntelCities BDIS top level data flow diagram

From the above figure, the centralized database accepts not only 3D building information but also Geo-Spatial information and other thematic information. This information integration greatly helps people doing holistic review and analysis of a building during the decision making process; Thus it is quite possible to do a report about the features of the whole building, and its relationship with surroundings. The following Figure 7 shows a report of windows and doors in Jactin House generated by the BDIS. And Figure 8 shows the building model captured from the 3D scanner is integrated with urban scale 3D model and GIS 2D data. 


\section{Scanning-Survey Report of Jactin House Elements - Windows and doors}

Generated from Centralized nD Database

There are together 199 windows, in 4 sides of Jactin House, located in 5 floors and in different size

- In each elevation of the Jactin House, the number of windows are:

Front elevation window-number: 82

Left elevation window-number: 40

Right elevation window-number: 22

Rear elevation window-number: 55

- The 199 windows are located in 5 floors (from the ground to the 4 th floor)

The ground floor window-number: 27

The 1st floor window-number: 47

The 2nd floor window-number: 56

The 3rd floor window-number: 43

The 4th floor window-number: 26

- There are 6 different types among all these windows

0) There are 34 windows of type 1: 1.7 (w) $\times 2.5$ (h)

1) There are 41 windows of type 2: 1.0 (w) $\times 2.5$ (h)

2) There are 29 windows of type $3: 0.5(\mathrm{w}) \times 1.7(\mathrm{~h})$

3) There are 33 windows of type 4: $0.60(\mathrm{w}) \times 1.3(\mathrm{~h})$, with a curved shape on top (radius: 0.3 )

4) There are 31 windows of type 5: $2.0(\mathrm{w}) \times 1.8(\mathrm{~h})$

5) There are 31 windows of type $6: 1.35(\mathrm{w}) \times 1.6(\mathrm{~h})$

- Windows size illustration:

hitt: $/ / 127.0 .0 .1 / \mathrm{jhm}$ ode/ $/$ Vin\&Doors $/$ Windows. gif

There are together 5 doors, in the front side and left side of Jactin House, in different size

- 4 of the doors are at the front of the house

- 1 of the cloors is at the left of the house

- Doors size illustration: http://127.0.0.1/3hmodel/Win\&Doors/Doors.gif

From the survey, it is suggested that all windows and doors need to be replaced.

A VRML model is generated following this report to show just the windows and doors around Jactin house

http://127.0.0.1/jhmodel/Win\&Doors/Jactin Housewindows.wrl

Figure 7: A report of the survey of windows and doors in Jactin House

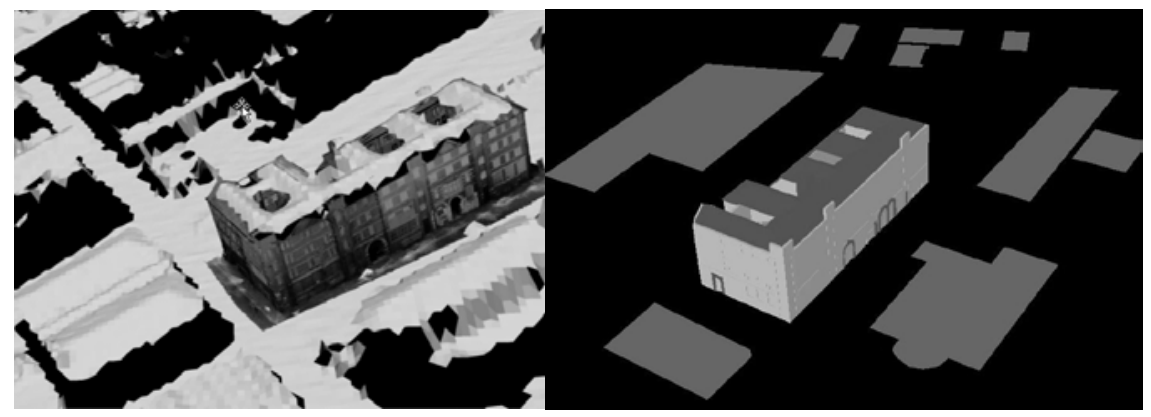

Figure 8: Merged Ground Based 3D building scanning with airborne scanning of the surrounding area (left), and converted scanning model was displayed with converted ESRI shape file (right) of Jactin House

However, the research recognized the fact that the data analysis is still problematic in terms of the automation on data processing, the post processing can still be very time consuming and depends on the required level of detail of the model.

However, there is much current research interest in fully automatic pattern matching and object recognition on both ground based laser scanning and airborne data, and some successful outcomes. Actually, the subsequent VEPS project that the authors were involved in also had a focus on object recognition (Wang 2008). 


\subsection{VEPS data sources}

The IntelCities 3D applitation based on the integrated building 3D scanning data and urban scale 3D data was described in Section 4.1. This sub-section 4.2 and the following sub-section 4.3 are going to introduce the VEPS web based 3D application design. As introduced in Section 1, a key activity of the VEPS project was to analyse large data sets, including high resolution 3D data from LiDAR and ground based scanning, for use within Virtual Reality (VR) visualisation software and the subsequent delivery of the VR environment via the Internet and World Wide Web. In the VEPS system, post-processed and converted 3D scanning data of buildings were also integrated into urban scale 3D data. The VEPS projet was concered with the delivery of 3D data through the web. This was achieved.using Web Services.

In the VEPS project, as in most geo-spatial related development, there are three kinds of datasets used: spatial data, thematic data and administrative data. However, spatial data is the core data for the 3D City Model. In VEPS data source definition, there are two kinds of spatial data: spatial basic data and Specific spatial data. Common to all VEPS test sites is a standard set of geographic data, the so called "spatial basic data". Further specific data (like noise simulation results) might differ between test sites. This data is called "Specific spatial data”. The related common standards are GML, IFC building model, CityGML (See also in Section 3).

In VEPS, 3D scanning data is seen as one of the available raw data collection methods. And the scanned 3D data set has to be processed and converted to be integrated with other "spatial basic data". This is actually a complex issue about data level interoperability in VEPS. XML based extended schema such as CityGML and other application schema are used as a common data model in this framework. The VEPS project saw improving the data level interoperability as a long term research ambition.

\subsection{VEPS application}

VEPS defined its user group as urban planners/architects, professionals, investors/project managers, citizens, and local authorities. The VEPS system requirements were therefore defined to include Geo-spatial planning information/commenting and communication between one to one and one to many. Requirements are: visualization and interactivity with map/3D scene, enquiry tool, secured user/data administration functions. From the users' point of view, system service is provided through the client interface. In order to provide an interface suitable for a wide range of users the VEPS system includes 3 main elements: 3D interaction, 2D interaction and communication facilities such as discussion forums and spatially located comments. These facilities are inter linked. 3D scanning data can play the role of a 3D data source to this application.

The VEPS concept architecture diagram reflects the VEPS user requirements see Figure 9. 


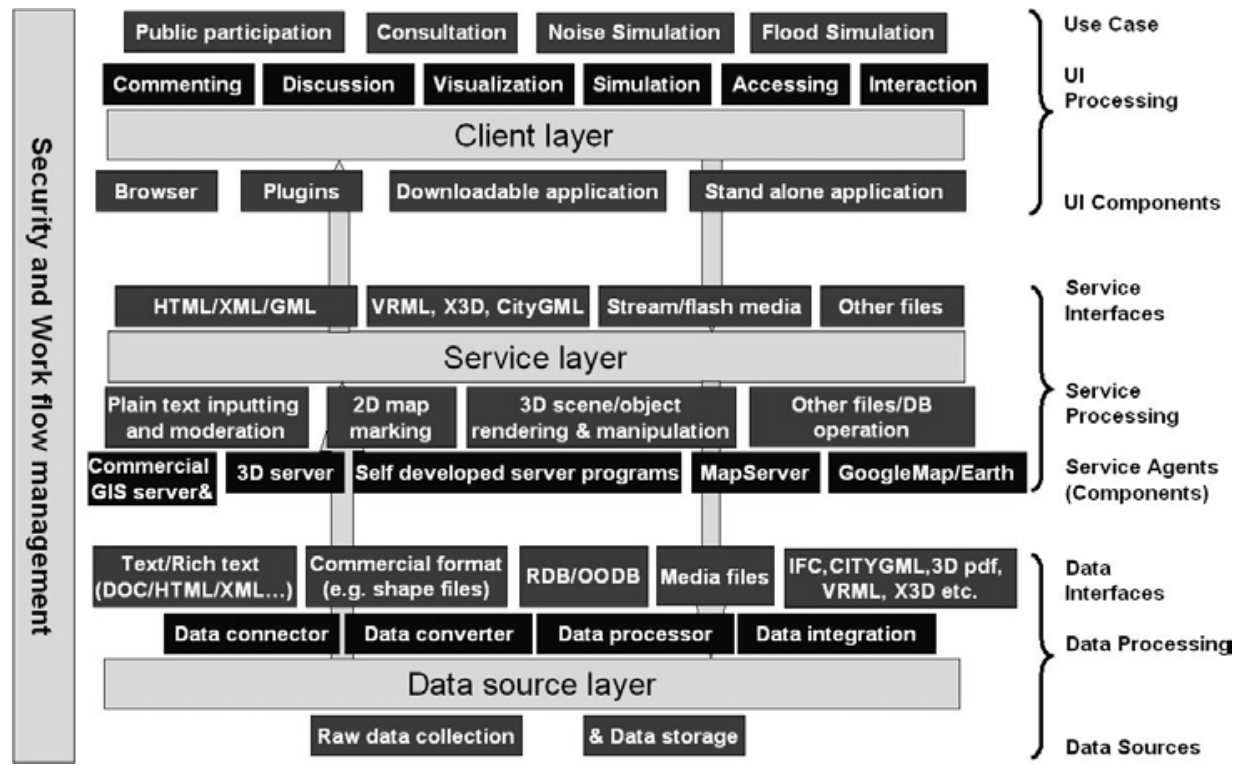

Figure 9 VEPS conceptual architecture

In the Figure 9, 3D scanning data is seen as means of raw data collection method. Underpinned by data sources, the system can provide various levels of functions to its users.

In VEPS project development, 2D, 3D and spatially related commenting modules were integrated to provide Internet users the ability to interact with urban scaled information. The post-processed and converted 3D scanning data of buildings were seen as a system data source to be integrated into urban scaled 3D data.

To summarize, this section reviews the IntelCities 3D application and the VEPS web 3D applications design. Both of the IntelCities and VEPS applications utilise integrated 3D scanned building data and urban scaled 3D data sets to provide service to users. The IntelCities application shows clearly services such as statistics of windows and doors of a building, and holistic review of the building and its surroundings. The design of VEPS application shows the possibilities to deliver integrated services across the Internet, and thus holistic views of whole urban environments can be made available to the public.

\section{Conclusion}

This paper reviews ground based 3D laser scanning technologies and it discusses the use and integration of 3D scanned building data with city scaled spatial data to build wide scale built environment models and to achieve holistic analysis. The authors believe this could be the solution for the two challenges that the traditional ways of creating city 3D models are facing. That brings us to the conclusion: 3D Laser scanning technology can be used to effectively produce 3D building model and as way of developing visual and 3D representations. In this review of recent research projects, the authors not only illustrated how complicated buildings can be captured in digital form with an accuracy that would not be possible without a 3D scanner, but also proved that the 3D data can be further processed and integrated with other sources of data (spatial or non-spatial) and thereby support construction professionals in making holistic analysis before coming to a decision. In the Virtual Environment Planning System (VEPS) project, it is also a proof of concept that 3D scanning 
data integrated with urban scaled 2D/3D data can be used to provide web based applications for participation and consultation. However, the authors still see the data level interoperability as a challenge in the integration process.

\section{References}

Arayici, Y., Hamilton A. (2005), Modeling 3D Scanned Data to Visualize the Built Environment, the 9th International Conference of Information Visualisation, London, 6,7,8 July 2005. pp. 509-514, ISBN: 0-7695-2397-8

Arayici, Y., Hamilton, A., Gamito, P., Albergaria, G., (2004) The Scope in the INTELCITIES Project for the Use of the 3D Laser Scanner, Proceeding of ECT2004: The Fourth International Conference on Engineering Computational Technology, 7-9 September 2004, Lisbon, Portugal. ISBN 0948749962 pp 111-112.

Arena 2000 project, (1999) Virtual Helsinki, http://www.virtualhelsinki.net/english/, Accessed in Nov 2004.

Bulmer, D. (2001). How Can Computer Simulated Visualizations of the Built Environment Facilitate Better Public Participation in the Planning Process? OnLine Planning Journal.

Chan, R., Jepson, William., Friedman, Scott. (1998). Urban Simulation: An Innovative Tool for Interactive Planning and Consensus Building. Proceedings of the 1998 American Planning Association National Conference, Boston, MA, USA.

Counsell, J., Littlewood, J., Arayici, A., Hamilton, A., et. (2008). Future Proofing, Recording and Tagging Historical Buildings: a Pilot Study in Wales, UK. Accepted for 2008 RICS COBRA Conference.

Ding, L., Liew, P, Maher, ML, Gero, JS and Drogemuller, R (2003). Integrating CAD and 3D Virtual Worlds Using Agents and EDM. CAAD Futures.

Dodge, M., Smith, A., Fleetwood, S. (1998). Towards the Virtual City: VR \& Internet GIS for Urban Planning. Virtual Reality and Geographical Information Systems, Birkbeck College.

Fuchs, C., E. Gülch and W. Förstner (1998). OEEPE Survey on 3D-City Models. Frankfurt, Bundesamt für Kartographie und Geodäsie

Hamilton A., Burns, M., Arayici, Y., Gamito, P., Marambio, A. E., Abajo, B., Pérez, J., Rodríguez-Maribona, I.A., (2005), Building Data Integration System, Final Project Deliverable in the Intelligent Cities (IntelCities) Integrated Project, IST - 2002-507860, Deliverable 5.4c, Final Report, September 2005, University of Salford, UK.

Howell, I., Batcheler, B. (2003). Building Information Modeling Two Years Later - Huge Potential, Some Success and Several Limitations. http://www.laiserin.com/features/bim/newforma_bim.pdf. 
IMS (2002) IFCsvr ActiveX Component Object Reference, VTT (Finland) and SECOM, Inc (Japan) http://cic.vtt.fi/projects/ifcsvr/ifcsvrr200/default.html

Jepson, W. H., Liggett, Robin. S.,Friedman,Scott. (2001). An Integrated Environment for Urban Simulation. Planning Support Systems: Integrating Geographic Information Systems, Models, and Visualization Tools. R. K. Brail and R. E. Klosterman. Redlands, California, USA, ESRI Press: 387-404.

Kolbe, T. H., Gröger, Gerhard., Plümer, Lutz. (2005). CityGML - Interoperable Access to 3D City Models. International Symposium on Geoinformation for Disaster Management GI4DM 2005, Delft, Netherlands,, Lecture Notes in Computer Science, Springer.

Kolbe, T., Bacharach, Sam. (2006). CityGML: An Open Standard for 3D City Models. Directions Magazine.

Shiode, N. (2001). 3D Urban Models: Recent Developments in the Digital Modelling of Urban Environments in Three-Dimensions. GeoJournal 52(3): 263-269.

Song, Y., Hamilton, A. and Wang, H. (2007) Built environment data integration using nD modelling, ITcon Vol. 12, pg. 429-442, http://www.itcon.org/2007/28

Tanyer, A. M., Tah, J. H. M., Aouad, G. (2005). Towards n-Dimensional Modelling in Urban Planning. Innovation in Architecture, Engineering \& Construction (AEC), Rotterdam.

Wang, H., Hamilton, A. (2005). Data Integration Issues within nD Information Model for Urban Planning. 5th International Postgraduate Research Conference, Salford, UK, Blackwell Publishing.

Wang, H., Hamilton, A., Counsell, J. and Tah, J. A web-based framework for urban data sharing and dynamic integration, in ACE: Architecture, City and Environment ISSN: 1886-4805 Publisher: Universitat Politecnia de Catalunya, Barcelona, Spain.

Wang, Y. (2008) a further discussion of 3D building reconstruction and roof reconstruction based on airborne LiDAR data by VEPS' partner, the Department of Remote Sensing and Land Information Systems, Freiburg University. http://portal.uni-freiburg.de/felis/Members/yw78/Topic2?set_language=en\&cl=en

Yao, J., Tawfik, H., Fernando, T. (2003). Supporting Collaborative Urban Planning with GIS and Virtual Reality. GISRUK, City University, London. 